\title{
Efetividade da participação cidadã nos conselhos municipais de Curitiba
}

\author{
Effectiveness of citizen participation in the municipal councils of Curitiba
}

Fabiana Marissa Ełzel Barddal[a] (D), Ricardo Lobato Torres[b] (D)

[a] Universidade Tecnológica Federal do Paraná (UTFPR), Curitiba, PR, Brasil

[b] Universidade Tecnológica Federal do Paraná (UTFPR), Programa de Pós-graduação em Planejamento e

Governança Pública, Curitiba, PR, Brasil

Como citar: Barddal, F. M. E., \& Torres, R. L. (2020). Efetividade da participação cidadã nos conselhos municipais de Curitiba. urbe. Revista Brasileira de Gestão Urbana, 12, e20190045. https://doi.org/10.1590/2175-3369.012.e20190045

\section{Resumo}

Este artigo avalia a efetividade da participação cidadã nos conselhos municipais de Curitiba. Um estudo de casos múltiplos foi realizado com foco nos conselhos sociais. Foi realizada uma pesquisa documental da legislação, dos regimentos internos e das atas de reuniões dos Conselhos Municipais de Alimentação Escolar, de Esporte e de Saúde, com o objetivo de identificar a possibilidade legal e a participação efetiva dos cidadãos nas sessões plenárias. Um tipo ideal de governança pública foi proposto a partir de uma síntese da revisão de literatura sobre o tema. A partir disso, foram definidas 18 variáveis qualitativas a serem identificadas nas atas das reuniões dos conselhos. No período de 2015 e 2016, a frequência relativa de ocorrência das variáveis nos conselhos estudados foi de $18 \%$, 10\% e $45 \%$, respectivamente. Conclui-se que, apesar da previsão legal da democracia participativa e do controle social, a participação cidadã ainda é limitada, caracterizando-se pela passividade dos representantes da sociedade civil. Além disso, há pouca transparência dos atos dos conselhos, evidenciada pela ausência de dados atualizados no Portal dos Conselhos Municipais de Curitiba ou em endereço eletrônico próprio, bem como pela forma sucinta de redação das atas das reuniões dos conselhos.

Palavras-chave: Democracia participativa. Controle social. Conselhos gestores de políticas públicas. Governança pública. Participação cidadã.

\section{Abstract}

This article evaluates the effectiveness of citizen participation in the municipal councils of Curitiba. A multiple case study was performed, which the focus was the social councils. Documentary research was carried out on the legislation, internal regulations and minutes of meetings of the Municipal Councils on School Feeding, Sports and Health, with the objective of identifying the legal possibility and the effective participation of citizens in plenary sessions. An ideal type of public governance was proposed from a synthesis of the literature review on the subject. From this, 18 qualitative variables were defined to be identified in the minutes of the council meetings. In the period of 2015 and 2016, the relative frequency of 
occurrence of the different variables in the councils studied was 18\%, 10\% and 45\%, respectively. It was concluded that, despite the legal prediction of participatory democracy and social control, citizen participation is still limited, characterized by the passivity of representatives of civil society. In addition, there is little transparency in the acts of the councils, evidenced by the absence of updated data in the Portal of the Municipal Councils of Curitiba or in its own electronic address, as well as by the succinct way of writing the minutes of the council meetings.

Keywords: Participatory democracy. Social control. Public policy management councils. Public governance. Citizen participation.

\section{Introdução}

Desde a década de 1990, o Brasil passou a ser considerado um laboratório de experiências de participação democrática nas três esferas de governo, embora haja registros de iniciativas anteriores durante o período da redemocratização do país. A Constituição da República Federativa do Brasil de 1988 (CRFB) foi um dos fatores determinantes para a proliferação dos conselhos gestores de políticas públicas (CGPP) em território nacional. Esse movimento tem permitido, em muitos casos, a atuação dos cidadãos como atores no processo decisório em âmbito governamental e tem contribuído para a instituição da gestão democrática nas cidades brasileiras (Fuks, 2004; Santos et al., 2004; Frey \& Duarte, 2006; Diegues, 2013; Lüchmann et al., 2016).

Além do estabelecimento dos CGPP, a CRFB trouxe outras possibilidades institucionais para promover a democracia participativa, sobretudo no âmbito urbano: orçamentos participativos, conferências públicas, consultas públicas etc. Desponta uma nova concepção de relacionamento entre Estado e sociedade civil, em que o controle social da administração pública não fica restrito aos órgãos de controle do próprio governo. A democracia participativa vem possibilitar o aumento da participação direta dos cidadãos na gestão pública, ampliando as possibilidades de eficiência e efetividade das políticas públicas, além de constituir princípio para formulação e monitoramento das ações governamentais, sob uma nova perspectiva de poder existente (Frey, 2004; Santos et al., 2004; Frey \& Duarte, 2006; Diegues, 2013; Dagnino \& Teixeira, 2014; Avritzer \& Ramos, 2016; Gohn, 2016; Lüchmann et al., 2016).

Para isso, a gestão pública democrática deve estar pautada em três elementos: a

[...] maior responsabilidade dos governos municipais em relação às políticas públicas e às demandas dos cidadãos; o reconhecimento dos direitos sociais; a abertura de canais para a ampla participação cívica da sociedade. (Santos et al., 2004, p. 13).

Frey \& Duarte (2006) alertam para um desafio a ser enfrentado pela democracia e gestão local: além da inclusão dos atores identificados como excluídos das decisões públicas (objetivo primordial das experiências brasileiras de democracia participativa), há a necessidade de inclusão dos chamados reclusos, ou seja, dos cidadãos dos

[...] setores mais abastados da sociedade que evidentemente viraram às costas ao espaço público, por já não precisar mais dele para perseguir seus interesses particulares. (Frey \& Duarte, 2006, p. 117).

Entre os canais de interlocução da sociedade civil com os governos locais, os CGPP apresentam maior potencial para a efetivação de uma cultura de democracia participativa no país. Considerando a descentralização administrativa e o reconhecimento dos municípios como entes da federação na CRFB (Bercovici, 2008), os CGPP representam a porta de acesso mais próxima à participação da sociedade civil na gestão pública.

Apesar da instituição legal dos conselhos ao final dos anos 1980, estudos mostram que foi ao longo dos anos 2000 que a maioria dos conselhos foi criada (Rojas Buvinich, 2014). A simples previsão legal desses conselhos, contudo, não é condição suficiente para garantir a inclusão da sociedade nos 
processos decisórios e de controle das ações governamentais. Em consonância com a necessidade de aprofundamento de pesquisas apontadas em estudos anteriores (Diegues, 2013; Rojas Buvinich, 2014; Gohn, 2016), este artigo tem por objetivo avaliar a efetividade da participação cidadã nos conselhos municipais a partir de um estudo de casos múltiplos da cidade de Curitiba.

Foi realizada uma análise sistemática de documentos dos conselhos municipais: leis de criação, regulamentos internos e atas de reuniões. Além disso, foi elaborado um quadro analítico com categorias relacionadas à participação nos conselhos, o qual permitiu avaliar o quão próximas essas instituições estão do tipo ideal de governança pública democrática. Para o estudo, foram selecionados os Conselhos Municipais de Alimentação Escolar, de Esporte e de Saúde.

0 artigo está dividido em cinco seções, incluindo esta introdução. Na segunda seção, é apresentada uma revisão de literatura sobre governança pública, com foco em duas correntes de pensamento: a tecnocrática e a democrático-participativa. A terceira seção apresenta o método da pesquisa. A quarta seção expõe e discute os resultados da pesquisa documental. Por fim, a quinta seção traz as conclusões.

\section{Revisão de literatura}

\section{Governança pública e democracia participativa}

Cepiku (2008) e Cozzolino \& Irving (2016) realizaram pesquisas em busca da definição do termo "governança pública" e, ao estudarem diversos autores e organizações que se dedicam a essa área, concluíram que ele é polissêmico.

Para Cepiku (2008), o movimento em prol da governança pública democrática seria uma resposta às falhas percebidas em outros modelos de gestão, entre elas a necessidade de aprimoramento na análise das demandas e dos interesses dos atores envolvidos, tanto para a formulação como para a execução de políticas públicas. Essa nova abordagem implica a necessidade de enfrentamento das falhas de resposta do poder público às necessidades dos cidadãos. Para a autora, a concepção de governança pública teria como resultado um processo social no qual a sociedade, com seus diversificados atores e seus segmentos marginalizados, seria chamada para o debate e a deliberação sobre as ações governamentais e as políticas públicas, principalmente em âmbito local.

Conforme Cozzolino \& Irving (2016), na administração pública a concepção de governança apresenta duas correntes distintas, resultantes de diferentes orientações ideológicas e visões de mundo: (1) governança tecnocrática; e (2) governança democrática ou democrático-participativa. Nesse sentido, o estudo parte da classificação de Cozzolino \& Irving (2016) para elaboração de uma definição e diretriz para a pesquisa.

A corrente da governança tecnocrática, embora defenda a inclusão de atores externos ao governo na gestão pública, o faz no sentido de que diferentes visões, saberes e potencialidades dos indivíduos contribuam para uma maior eficiência e efetividade dos processos de gestão. Inspirada na governança corporativa, busca a modernização e o enxugamento do Estado por meio da ampliação do número de envolvidos nos processos de tomada de decisão. A autonomia da esfera executivo-administrativa é considerada como basilar para o estabelecimento da transparência e da accountability, aspectos essenciais em países que carecem de uma cultura política de controle social dos agentes governamentais - e entre esses países estaria o Brasil (Cozzolino \& Irving, 2016).

A corrente democrática tem como objetivo central a emancipação social e política. Incentiva a organização e o fortalecimento da sociedade civil a fim de fomentar mecanismos de tomada de decisão em instituições públicas que privilegiem a interlocução entre sociedade civil e Estado. Essa abordagem entende como fundamental a postura ativa dos setores sociais nas instâncias decisórias sem defender, no entanto, o afastamento do Estado de seus papéis de coordenação das ações planejadas e de mediação entre os cidadãos (Cozzolino \& Irving, 2016). 
Nesse contexto, as atitudes ou os valores democráticos dos atores envolvidos na gestão pública são requisitos importantes para o funcionamento e a qualidade da democracia. Como exemplos desses valores ou atitudes estão a tolerância política, as eleições, a participação e o próprio apoio à democracia (Fuks \& Casalecchi, 2018).

A principal diferença entre a governança pública de cunho tecnocrático e a de cunho democrático ou democrático-participativa é que, na primeira, "[...] a orientação é o interesse público estatal e o protagonismo é do Estado", enquanto, na segunda, “[...] a orientação é o interesse público não estatal e o protagonismo, da sociedade" (Alcântara et al., 2015, p. 11).

Pesquisadores como Frey (2004), Paula (2005), Santos et al. (2004), Gohn $(2004,2011)$ e Dias \& Cario (2017) defendem a necessidade da participação da sociedade civil na gestão pública, a fim de garantir a implementação de espaços democráticos e de uma administração pública participativa ou interativa. Nesses espaços, o poder de tomada de decisão dos governantes seria compartilhado com a sociedade civil, criando-se, assim, uma complementaridade entre a democracia participativa e a democracia representativa, sem que uma se sobreponha à outra.

O modelo de administração pública gerencial, ainda presente no Brasil, com seus aspectos positivos, possibilitou alguma melhora na eficiência dos serviços públicos, principalmente no campo econômicofinanceiro (Paula, 2005). Porém, a implementação da governança pública democrática vai além, exigindo dos governantes um compromisso com os princípios "[...] de transparência (disclosure); equidade (fairness); prestação de contas (accountability); cumprimento das leis (compliance); e ética" (Matias-Pereira, 2010, p. 125).

0 Estado deve estar bem estruturado para atender às necessidades e demandas da sociedade por meio de serviços públicos de qualidade (Matias-Pereira, 2010). Assim, Paula (2005) salienta que as três dimensões da gestão pública precisam ser articuladas e consideradas: institucional-administrativa; econômico-financeira; sociopolítica.

Na vertente da governança pública democrática, o Estado assume a figura de agente cooperativo na localidade, além de ativador e coordenador das inter-relações entre os diferentes atores, devendo tornar-se mais democrático, transparente, político e participativo (Paula, 2005; Dias \& Cario, 2017). Do poder público almeja-se a mediação da arena participacionista e dos conflitos entre os diferentes atores, além do fomento aos processos de interação dos grupos de interesse (Estado, sociedade e mercado). Pretende-se, com isso, uma perspectiva viável de diálogo em busca de um retrato mais positivo dos espaços públicos e compartilhados (Frey \& Duarte, 2006; Dias \& Cario, 2017). A sociedade, por meio do engajamento dos cidadãos, deve ser mais atuante na gestão pública em prol da apresentação de demandas e da elaboração de propostas tanto de desenvolvimento como de solução de problemas (Paula, 2005; Dias \& Cario, 2017).

Portanto, o artigo adota a definição de governança pública democrática como uma forma de gestão pública na qual o poder público e a sociedade civil interagem para a elaboração e o acompanhamento das políticas públicas. Para sua efetivação, os cidadãos precisam ser proativos, exigindo que o poder público realize uma gestão responsável, utilizando, de maneira eficiente e efetiva, os recursos públicos e visando à geração do bem-estar coletivo. Os cidadãos devem ser os principais interessados em saber onde os recursos públicos estão sendo aplicados e o que está sendo alcançado com eles (Matias-Pereira, 2010).

O compartilhamento do poder entre governo e sociedade requer a aquisição de conhecimento e compreensão sobre a temática da participação por parte dos cidadãos, para que estes discutam e deliberem em igualdade com o poder público. Os CGPP demandam a atuação de cidadãos qualificados, uma vez que estes possuem direito à voz e ao voto, assegurando-se, assim, legitimidade e autoridade moral na representatividade (Gohn, 2016). Logo, os conselhos precisam ser dotados de diferentes tipos de recurso, inclusive o de formação ou capacitação técnica e política contínua dos conselheiros, pois os atores têm diferentes níveis de conhecimentos e entendimentos sobre os assuntos envolvidos nas deliberações (Martins et al., 2014; Gohn, 2016).

Além disso, a gestão fundamentada na governança pública democrática sugere o fomento às instituições com base em princípios de liberdade, igualdade, responsabilidade, participação na tomada 
de decisão e promoção da inclusão dos setores mais vulneráveis da sociedade. Está relacionada a aspectos como: incentivar e fortalecer a interação presencial entre os grupos locais e diferentes atores com a esfera pública; agregar grupos vulneráveis às discussões e deliberações e excluídos delas, possibilitando a redução do impacto das relações assimétricas de poder; viabilizar práticas e estruturas horizontais de participação que permitam a produção de capital social (Santos et al., 2004).

\section{Conselhos gestores de políticas públicas como instrumentos de governança pública}

No Brasil, os CGPP apresentam-se como experiências com forte potencial democrático. São arenas de discussão em que é possível exercer o controle social sobre o Estado e participar das decisões políticas, abordando problemas, demandando novos direitos por parte do cidadão e de grupos sociais e possibilitando concretizar inserções na agenda política do Estado (Martins et al., 2014; Kleba et al., 2015; Gohn, 2016).

Os CGPP são instituições de controle não correcionais, ou seja, não possuem recursos coercitivos respaldados legalmente para aplicar sanções. Não lhes é permitido sancionar, com rigor, os agentes do governo ou os próprios conselheiros, uma vez que estes são corresponsáveis por desvios que porventura aconteçam. Todavia, podem agir corretivamente a partir de resultados e sobre as políticas (Gomes, 2015).

Essas características dos CGPP podem ser garantidas por meio da definição das competências nas leis de criação e nos regimentos internos, na forma de composição da estrutura organizacional, bem como nas condutas de cada conselho. Assim, estudar a institucionalização, a representação, as competências e o resultado da fusão dessas características é fundamental para compreender como tem sido concretizado o funcionamento dos conselhos gestores (Gomes, 2015; Kleba et al., 2015).

Na arquitetura da participação brasileira, os CGPP podem ser constituídos pelo cidadão comum, pela sociedade organizada e pelo poder público, sendo vinculados a diversas áreas públicas e temáticas transversais. A rápida regulamentação pela legislação auxiliou no aumento significativo do número de CGPP, estando alguns conselhos presentes em quase todos os municípios brasileiros (Rojas Buvinich, 2014; Dagnino \& Teixeira, 2014; Gomes, 2015; Kleba et al., 2015; Gohn, 2016; Pereira et al., 2016).

Os CGPP podem ser definidos como

[...] espaços públicos vinculados a órgãos do Poder Executivo, tendo por finalidade permitir a participação da sociedade na definição de prioridades para a agenda política, bem como na formulação, no acompanhamento e no controle das políticas públicas. (IPEA, 2013, p. 9).

Na Lei Orgânica Municipal de Curitiba, está estabelecida a garantia da participação popular nas decisões governamentais. Em seu artigo 79, determina que a criação de conselhos municipais nas diversas áreas atenderá aos princípios da democracia participativa e contará com representantes populares que sejam usuários dos serviços públicos (Curitiba, 2011).

A participação da sociedade civil precisa ter caráter deliberativo nos CGPP. Isso permite que essas instituições possam ter a prerrogativa de intervir em assuntos de interesses coletivos nas suas áreas de atuação, inclusive com a possibilidade de articulação com outros conselhos, no caso de políticas intersetoriais. A vantagem dessa articulação entre as políticas é a possibilidade do enfrentamento de problemas complexos de maneira integrada na administração pública (Martins et al., 2014).

Os CGPP não apresentam um padrão de funcionamento. Em algumas temáticas ou setores, são obrigatórios para o repasse de recursos federais e estaduais, possuindo funções diversificadas para as políticas públicas. As variações entre os conselhos podem acontecer também decorrentes do perfil das organizações da sociedade civil envolvidas e de como está previsto o equilíbrio entre as representações governamentais e não governamentais (paritário, tripartite etc.). São justamente as distinções entre eles que favorecem a análise dos indicadores de participação e mobilização da sociedade civil (Santos et al., 2004; Avritzer, 2008; Diegues, 2013; Rojas Buvinich, 2014; Dagnino \& Teixeira, 2014; Almeida et al., 2015; Gomes, 2015; Lüchmann et al., 2016; Gohn, 2016). 
A composição dos conselhos possibilita, nomeadamente, a incorporação de um número reduzido de representantes. Os conselheiros geralmente são designados democraticamente, sendo que, para cada conselheiro representante do Estado, preconiza-se um representante da sociedade civil, no mínimo (Avritzer, 2008; Dagnino \& Teixeira, 2014; Almeida et al., 2015; Gomes, 2015). Há exceções à regra da paridade, como o caso dos conselhos de saúde, que são compostos considerando a paridade de $50 \%$ de entidades de usuários, $25 \%$ de entidades de trabalhadores, $12,5 \%$ de gestores e $12,5 \%$ de prestadores de serviços na área da saúde (Curitiba, 2018).

Como instâncias participativas e decisórias, os conselhos contribuem para a politização do cidadão por causa de seu caráter pedagógico de promover o aprendizado da convivência democrática. Têm potenciais para induzir uma transformação das concepções dos cidadãos em relação ao seu papel político, construindo, a partir disso, uma cultura política democrática fortalecida por meio de espaços de liberdade e igualdade (Martins et al., 2014; Kleba et al., 2015; Gohn, 2016).

Avritzer (2008) destaca que, para evitar que o conselho gestor se torne ineficaz, é necessário superar a hostilidade do sistema político e a fraqueza da sociedade. Isso dependerá de uma forte organização da sociedade civil e da vontade política dos governantes em apoiar os processos participativos. 0 desenvolvimento de práticas sociais, possibilitadas pelos conselhos, tende a construir saberes e valores cidadãos envolvendo a participação de pessoas que, mesmo sendo diferentes, lutam por metas que visam ao bem coletivo (Gohn, 2016). Para Santos et al. (2004, p. 21), os conselhos "[...] são a maior expressão da instituição, pelo menos no plano legal, do modelo de governança democrática no âmbito local."

No entanto, é necessário o reconhecimento de que, além de os conselhos poderem atuar como canais de interlocução entre Estado e sociedade civil, podem atuar como canais para apenas referendar as decisões centralizadoras do Estado, o que justifica a necessidade dos estudos sobre o tema.

\section{Métodos}

Foi realizado um estudo de casos múltiplos para avaliar a efetividade da participação dos cidadãos nos CGPP na cidade de Curitiba. Foi utilizada a pesquisa documental, a qual foi dividida em duas categorias de documentos: a primeira foi direcionada para as leis de criação e os regimentos internos dos conselhos selecionados, cujo foco de análise foi avaliar a sua organização institucional, forma de representação dos membros governamentais e não governamentais, bem como suas competências; a segunda, a partir de pesquisa nas atas das reuniões ordinárias e extraordinárias, fez a avaliação da efetividade da participação cidadã nos referidos conselhos.

0 cerne da pesquisa foram os conselhos classificados como sociais no Portal dos Conselhos Municipais de Curitiba (2018). Esse primeiro recorte deveu-se ao fato de os conselhos sociais representarem as áreas de interesse imediato da população e também por terem o potencial de atuar diretamente na formulação das políticas sociais, uma vez que existe a presença da sociedade civil na composição colegiada dos conselhos.

Além da classificação como conselhos sociais, foram utilizados como segundo recorte de pesquisa os conselhos que disponibilizavam no Portal, de julho de 2017 a julho de 2018, todas as fontes de coleta de dados adotadas pela pesquisa: lei de criação e/ou regimento interno e todas as atas das reuniões plenárias dos anos de 2015 e 2016.

De um total de 48 conselhos constantes no Portal, 21 são definidos como conselhos sociais, dos quais, no entanto, apenas 3 disponibilizavam todas as fontes de coleta de dados para a pesquisa, embora com uma diferença natural no número de reuniões em cada instituição: Conselho Municipal de Alimentação Escolar (CAE), Conselho Municipal de Esportes (CME) e Conselho Municipal de Saúde (CMS).

Foi utilizada a técnica de análise de conteúdo nos documentos elencados, objetivando identificar a institucionalização, a forma de representação, as competências, e as características da governança pública democrática presentes em cada um dos três conselhos. Tais características foram organizadas em 9 categorias, 15 subcategorias analíticas e 18 variáveis operacionais a serem investigadas, conforme demonstrado na Tabela 1. 
Tabela 1 - Categorias, subcategorias e variáveis analíticas para avaliação dos conselhos

\begin{tabular}{|c|c|c|c|c|c|}
\hline $\mathrm{C}$ & CATEGORIA & SC & SUBCATEGORIA & V. & VARIÁVEIS OPERACIONAIS \\
\hline $\mathrm{Cl}$ & $\begin{array}{l}\text { Interlocução entre Estado, } \\
\text { mercado e sociedade civil }\end{array}$ & - & - & $\mathrm{V} 1$ & $\begin{array}{l}\text { Percebem-se participação e diálogo entre as } \\
\text { três esferas: Estado, mercado e sociedade civil }\end{array}$ \\
\hline \multirow{3}{*}{ C2 } & \multirow{3}{*}{$\begin{array}{l}\text { Democracia participativa e } \\
\text { deliberativa sob o enfoque } \\
\text { pluralista, por meio de } \\
\text { representantes e de forma direta }\end{array}$} & SC2.1 & $\begin{array}{l}\text { Democracia participativa } \\
\text { representativa no conselho }\end{array}$ & V2.1 & $\begin{array}{l}\text { Registro de pronunciamento de conselheiro } \\
\text { da área não governamental }\end{array}$ \\
\hline & & SC .2 & $\begin{array}{l}\text { Democracia participativa direta do } \\
\text { cidadão no conselho (prática efetiva) }\end{array}$ & V2.2 & $\begin{array}{l}\text { Registro de pronunciamento de cidadão não } \\
\text { conselheiro }\end{array}$ \\
\hline & & $\mathrm{SC} 2.3$ & Democracia deliberativa no conselho & V2.3 & $\begin{array}{c}\text { Registro de deliberações sobre a temática do } \\
\text { conselho relacionadas às políticas públicas } \\
\text { e/ou ações governamentais }\end{array}$ \\
\hline \multirow{4}{*}{ C3 } & \multirow{4}{*}{$\begin{array}{l}\text { Planejamento, implementação, } \\
\text { controle das ações } \\
\text { governamentais e das políticas } \\
\text { públicas, e fiscalização do uso de } \\
\text { recursos públicos }\end{array}$} & SC3.1 & $\begin{array}{l}\text { Consulta sobre as ações } \\
\text { governamentais e políticas públicas } \\
\text { de sua temática }\end{array}$ & V3.1 & $\begin{array}{l}\text { O conselho, em algum momento, foi } \\
\text { consultado sobre ações governamentais e } \\
\text { políticas públicas, antes que estas já } \\
\text { estivessem definidas pelo poder público sobre } \\
\text { sua implementação }\end{array}$ \\
\hline & & SC3.2 & $\begin{array}{l}\text { Planejamento sobre as ações } \\
\text { governamentais e políticas públicas } \\
\text { de sua temática }\end{array}$ & V3.2 & $\begin{array}{l}\text { Identifica-se situação explícita de } \\
\text { planejamento de ações governamentais e } \\
\text { políticas públicas }\end{array}$ \\
\hline & & $\mathrm{SC} 3.3$ & $\begin{array}{l}\text { Controle social das ações } \\
\text { governamentais e políticas públicas } \\
\text { de sua temática }\end{array}$ & V3.3 & $\begin{array}{l}\text { O conselho realizou controle social sobre as } \\
\text { ações governamentais e políticas públicas } \\
\text { (por exemplo, averiguou se determinada } \\
\text { aquisição chegou ao destinatánio nas } \\
\text { condições estabelecidas; verificou a } \\
\text { implementação de determinada ação etc.) }\end{array}$ \\
\hline & & SC3.4 & $\begin{array}{l}\text { Fiscalização do uso de recursos } \\
\text { públicos nas ações governamentais e } \\
\text { políticas públicas de sua temática }\end{array}$ & V3.4 & $\begin{array}{l}\text { Identifica-se análise de prestação de contas e } \\
\text { de recursos públicos pelo conselho }\end{array}$ \\
\hline $\mathrm{C} 4$ & $\begin{array}{l}\text { Incorporação de grupos vulneráveis e } \\
\text { excluídos às discussões e deliberações }\end{array}$ & SC4.1 & $\begin{array}{c}\text { Grupos vulneráveis estão representados no } \\
\text { conselho e participam das discussões e/ou } \\
\text { deliberações }\end{array}$ & V4.1 & $\begin{array}{l}\text { Grupos vulneráveis estão representados no conselho } \\
\text { e participam das discussões e/ou deliberações }\end{array}$ \\
\hline
\end{tabular}

SC4.2 Identificam-se grupos vulneráveis externos V4.2 Estão registradas presenças de grupos vulneráveis ao conselho nas reuniões

Continuidade e constância na

C5 participação, na deliberação e no controle social pela sociedade civil

Formação e capacitação técnica C6 e política, contínua dos atores envolvidos com as instituições de democracia participativa

Abertura do governo para aceitar C7 propostas oriundas da sociedade civil

SC7.

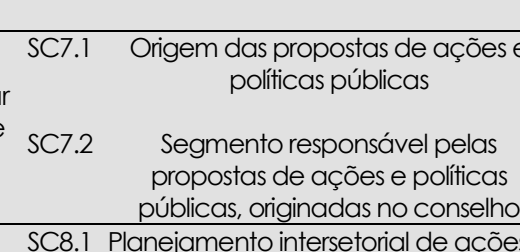
$\begin{array}{cc}\text { SC7.1 } & \begin{array}{c}\text { Origem das propostas de ações } \\ \text { políticas públicas }\end{array} \\ \text { SC7.2 } & \begin{array}{c}\text { Segmento responsável pelas } \\ \text { propostas de ações e políticas } \\ \text { públicas, originadas no conselho }\end{array} \\ \text { SC8.1 } & \text { Planejamento intersetorial de açõe }\end{array}$ externos ao conselho

V5 A ata traz registro das presenças dos conselheiros da sociedade civil (lista de presença ou registro de fala destes atores)

Conselheiros pariciparam de capacitações

V6 Conselheiros participaram de capacitações
técnicas e/ou políticas SC8.1 Planejamento intersetorial de ações e V8.1
políticas públicas

Intersetorialidade das políticas

C8 públicas e solução integrada dos problemas

SC8.2 Solução integrada de problemas

SC9.1 Deliberação de assuntos referentes à V9. descentralização políticoadministrativa

Descentralização políticoC9 administrativa (convênios, acordos, parcerias de maneira geral)

Descentralização políticoadministrativa existente
V8.2 Há registro de solução integrada de problemas

V7.1 Identificam-se propostas de ações e políticas públicas, originadas no próprio conselho

V7.2 Propostas nas quais se identificam como autores os representantes da área não governamental do conselho ou atores externos

Identifica-se relato de planejamento intersetorial de ações governamentais e políticas públicas Identificam-se deliberações referentes à descentralização político-administrativa (convênios, acordos, parcerias de maneira geral) a serem assumidas pela gestão pública

V9.2 Percebem-se situações de descentralização político-administrativa já em andamento na gestão sobre a temática do conselho

$C=$ categoria; $S C=$ subcategoria; $V$ = variáveis operacionais. Fonte: Elaborada pelos autores (2019). 
Durante a leitura das atas, foram registradas em uma planilha eletrônica as ocorrências de cada variável. 0 registro das variáveis pautou-se pela seguinte classificação: 0 (zero) quando a variável estivesse ausente na ata e 1 (um) quando a variável estivesse presente.

Posteriormente, foi criado um indicador relativo de ocorrências de cada variável, o que torna as variáveis comparáveis entre os diferentes conselhos. Esse indicador resultou da razão do somatório das ocorrências das variáveis nas atas analisadas pelo total de ocorrências possíveis, dada pela quantidade de atas de reuniões do período.

O número de possibilidades de ocorrência das variáveis dependia do número de reuniões de cada conselho em cada ano de análise. Portanto, o número total de possibilidades de ocorrência foi obtido pela multiplicação do número de variáveis operacionais (18 variáveis, conforme Tabela 1) pelo número de reuniões de cada conselho em cada ano. Desse modo, foi possível apresentar a frequência relativa das variáveis nas reuniões dos conselhos. Os resultados apresentados nesta pesquisa são reflexos dos registros em ata. Identificar as variáveis dependeu da redação daqueles documentos.

\section{Resultados e discussão}

\section{Análise da legislação}

A previsão legal é um dos aspectos fundamentais para que a participação cidadã possa se concretizar. A análise da capacidade de participação inicia-se com o diagnóstico da institucionalização (criação dos conselhos e formalização das suas regras de funcionamento), da representação (forma de composição ou definição dos conselheiros; paridade entre as representações das áreas governamental e não governamental) e das competências dos conselhos (capacidades ou funções). Essas três características são as responsáveis pelo desenho institucional dos conselhos e por estabelecer a possibilidade e o alcance da participação da sociedade civil nessas instituições.

Corroborando estudos anteriores que descrevem que a maioria dos conselhos do Brasil surgiu a partir da década de 1990 (Almeida et al., 2015; Avritzer \& Ramos, 2016; Gohn, 2016; Pereira et al., 2016), o CAE foi criado em 1995, o CME, em 2015, e o CMS, em 1991. Esse cenário reflete o impulso dado pela CRFB para a criação e o funcionamento de instituições de democracia participativa, objetivando a interlocução entre Estado e sociedade civil para as definições das políticas públicas.

As leis de criação e os regimentos internos dos conselhos analisados evidenciam a atribuição de múltiplas competências legais a essas instituições, conforme demonstrado na Tabela 2.

Tabela 2 - Atribuições específicas definidas nas legislações do CAE, CME e CMS

\begin{tabular}{cccccc}
\hline \multirow{2}{*}{ Conselho } & \multicolumn{5}{c}{ Atribuições detalhadas } \\
\cline { 2 - 6 } & Consultivo & Deliberativo & Controlador & Fiscalizador & Normativo \\
\hline $\mathrm{CAE}$ & $\mathrm{X}$ & $\mathrm{X}$ & $\mathrm{X}$ & $\mathrm{X}$ & $\mathrm{X}$ \\
$\mathrm{CME}$ & $\mathrm{X}$ & $\mathrm{X}$ & $\mathrm{X}$ & $\mathrm{X}$ & $\mathrm{X}$ \\
$\mathrm{CMS}$ & $\mathrm{X}$ & $\mathrm{X}$ & $\mathrm{X}$ & $\mathrm{X}$ & \\
\hline
\end{tabular}

CAE = Conselho Municipal de Alimentação Escolar; CME = Conselho Municipal de Esportes; CMS = Conselho Municipal de Saúde. Fonte: Elaborada pelos autores (2018).

Os três conselhos são deliberativos, uma das competências mais importantes para a efetiva participação da sociedade civil. 0 escopo das deliberações é bastante amplo: poder na decisão sobre o formato, estratégias e direcionamento das políticas públicas, aprovação orçamentária, prioridades de investimentos, assegurando, assim, a universalização de direitos sociais, o controle público sobre o governo, entre outros assuntos (Martins et al., 2014; Rojas Buvinich, 2014).

Além da atribuição deliberativa, esses conselhos apresentam atribuições controladora e fiscalizadora, competências fundamentais para o controle social das ações governamentais. Atribuições 
consultivas também foram identificadas para os três conselhos, no entanto a atribuição normativa está contemplada apenas pelo CMS.

Em relação à forma de composição dos conselhos, algumas diferenças foram constadas, conforme sintetizado na Tabela 3.

Tabela 3 - Forma de composição do CAE, CME e CMS

\begin{tabular}{|c|c|c|c|c|c|c|c|c|c|c|}
\hline \multirow{3}{*}{ Conselho } & \multicolumn{7}{|c|}{ Formas de composição } & \multicolumn{3}{|c|}{ Número de representantes } \\
\hline & \multicolumn{2}{|c|}{$\begin{array}{c}\text { Composição por } \\
\text { eleição }\end{array}$} & \multicolumn{2}{|c|}{$\begin{array}{l}\text { Entidades } \\
\text { predefinidas }\end{array}$} & \multicolumn{2}{|c|}{$\begin{array}{c}\text { Indicação de } \\
\text { autoridade }\end{array}$} & \multirow{2}{*}{ Mista } & \multirow{2}{*}{ 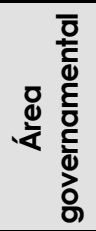 } & \multirow{2}{*}{ 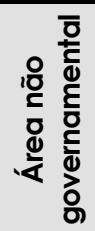 } & \multirow{2}{*}{ 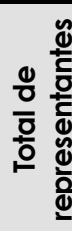 } \\
\hline & $\tilde{N} G o v$ & Gov & $\tilde{\mathbf{N}}$ Gov & Gov & $\tilde{N}$ Gov & Gov & & & & \\
\hline CAE & $\bar{x}$ & & & & & $\bar{x}$ & $\bar{x}$ & 3 & 4 & 7 \\
\hline CME & & & $x$ & $x$ & $x$ & $x$ & $x$ & 7 & 7 & 14 \\
\hline CMS & $x$ & & & $x$ & & $x$ & $x$ & 9 & 27 & 36 \\
\hline Total & 2 & 0 & 1 & 2 & 1 & 3 & 3 & 19 & 38 & 57 \\
\hline
\end{tabular}

CAE = Conselho Municipal de Alimentação Escolar; CME = Conselho Municipal de Esportes; CMS = Conselho Municipal de Saúde; ÑGov = não governamental; Gov = governamental. Fonte: Elaborada pelos autores (2018).

Os três conselhos contemplam a forma de composição mista. Dois deles, CAE e CMS, adotam composição por eleições para os representantes da área não governamental. O CME apresenta composição com entidades predefinidas para ambos os segmentos, sendo que os representantes delas são estabelecidos por indicação de seus dirigentes. A área governamental é estipulada por indicação de autoridade em todos os conselhos, com uma diferença para o CAE, cujos representantes da área governamental não são de entidades predefinidas, ou seja, há uma rotatividade no assento desse segmento.

Martins et al. (2014) defendem como princípio básico da representação a autonomia da sociedade civil na escolha de seus representantes por meio de eleição, para que o conselheiro se legitime diante do segmento que irá representar. Para Bevir (2010), a composição do conselho por eleições diretas seria uma alternativa para encorajar formas mais pluralistas e participativas de democracia, substituindo a indicação de representantes por autoridades e por entidades predefinidas.

Já a existência de entidades predefinidas na composição dos conselhos limita a institucionalização da democracia participativa. Como os conselheiros são indicados por autoridades das instituições, a possibilidade de acesso dos cidadãos em geral como membros do conselho é consideravelmente limitada.

A Tabela 3 também permite identificar que, no CME, os assentos são distribuídos em números iguais entre os dois segmentos, enquanto o CAE e o CMS contemplam mais conselheiros não governamentais. Constata-se, assim, que os três conselhos cumprem a premissa de ser instituições colegiadas, embora com diferentes números de representantes.

Esses conselhos estabelecem uma estrutura de funcionamento com potencial para deslocar as discussões e as deliberações, antes restritas ao poder público, para a sociedade civil. Esse deslocamento remete ao desafio da inclusão dos cidadãos como atores ativos na formulação das políticas públicas, os quais passariam a assumir a corresponsabilidade pela gestão pública, conforme defendido por Martins et al. (2014) e Kleba et al. (2015).

Nesse sentido, foi pesquisada a possibilidade de atores externos participarem das reuniões plenárias dos conselhos como ouvintes e/ou com direito à voz. Foi verificado que, no CME e no CMS, as reuniões são públicas e abertas à participação dos interessados; já a legislação do CAE não traz essa especificação. 


\section{Análise das atas de reuniões}

A adoção, pela Lei Orgânica Municipal de Curitiba (2011), da garantia da participação popular nas decisões do poder público e do fomento aos conselhos gestores é conquista a ser considerada. Essa lei estabelece, inclusive, a participação de representantes populares que sejam usuários dos serviços públicos municipais nos conselhos.

Todavia, a previsão legal isoladamente não é o suficiente para que sejam percebidos resultados da participação popular. É preciso que a sociedade civil seja consultada sobre suas demandas, bem como tenha o direito de deliberar sobre as ações governamentais e as políticas públicas relacionadas à temática do conselho.

A análise de conteúdo das atas foi um dos recursos utilizados para identificar as variáveis operacionais da pesquisa nos conselhos estudados. No entanto, a qualidade das redações das atas foi um dos limitantes da pesquisa.

O CAE realizou 22 reuniões plenárias no período estudado, sendo 13 em 2015 e 9 em 2016. A forma como foram redigidas as atas das reuniões plenárias do CAE foi uma das dificuldades na coleta de dados da pesquisa. As atas eram registradas em formato de memória da reunião, apresentando apenas os assuntos tratados na reunião e suas definições, porém não traziam detalhes das discussões ocorridas. Constavam também nas atas os nomes dos conselheiros e atores externos presentes nas plenárias, porém não estava registrado quem se manifestou sobre cada assunto.

O CME se reuniu cinco vezes em 2015 e seis vezes em 2016. As atas do CME foram redigidas de maneira a registrar os assuntos tratados nas reuniões, quem fez a explanação e quem fez questionamentos e solicitações de esclarecimentos. Nelas não estavam registrados todos os conselheiros presentes nas reuniões plenárias, apenas os que se manifestaram por meio de voz.

O CMS realizou 18 reuniões em 2015 e 16 em 2016. A forma de registro das atas do CMS permitiu a coleta de dados com maiores detalhes, pois foram transcritos todos os diálogos ocorridos nas reuniões por causa de o conselho possuir um sistema de gravação de áudio. Isso permitiu constatar a ocorrência de discussões e argumentações dos assuntos em pauta, além das votações de pautas previamente definidas.

A Tabela 4 retrata o número de possibilidades de detectar as variáveis operacionais constantes na Tabela 1 nas atas de cada conselho, o total de variáveis efetivamente identificadas e sua razão percentual.

Tabela 4 - Frequência absoluta e relativa das variáveis de governança pública democrática no CAE, CME e CMS (2015 e 2016)

\begin{tabular}{|c|c|c|c|c|c|c|c|c|c|}
\hline \multirow{2}{*}{ Descrição dos dados } & \multicolumn{3}{|c|}{ CAE } & \multicolumn{3}{|c|}{ CME } & \multicolumn{3}{|c|}{ CMS } \\
\hline & 2015 & 2016 & Total & 2015 & 2016 & Total & 2015 & 2016 & Tota \\
\hline Possibilidades de ocorrência & 234 & 162 & 396 & 90 & 108 & 198 & 324 & 288 & 612 \\
\hline Frequência absoluta & 43 & 29 & 72 & 11 & 19 & 30 & 141 & 136 & 277 \\
\hline Frequência relativa & $18 \%$ & $18 \%$ & $18 \%$ & $12 \%$ & $18 \%$ & $15 \%$ & $44 \%$ & $47 \%$ & $45 \%$ \\
\hline
\end{tabular}

CAE = Conselho Municipal de Alimentação Escolar; CME = Conselho Municipal de Esportes; CMS = Conselho Municipal de Saúde. Fonte: Elaborada pelos autores (2018).

Em 2015, de um total de 234 possibilidades de identificação de variáveis no CAE, foram encontradas 43 confirmações em atas, o que equivale à presença de 18\% de ocorrências. Em 2016, o número de reuniões foi menor, diminuindo as possibilidades de detecção das variáveis para 162. Desse total, foram identificadas 29 ocasiões em que algumas variáveis estavam presentes nas reuniões. Analisando-se os dois anos pesquisados juntamente, das 396 possibilidades de as variáveis serem contempladas no CAE, isso aconteceu 72 vezes, o equivalente a $18 \%$ das possibilidades.

Os dados detectados para o CME são menores. Em 2015, havia 90 possibilidades de identificar variáveis, porém foram detectados 11 acontecimentos (12\%). No ano de 2016, foram realizadas mais reuniões, atingindo 108 possibilidades de verificar as variáveis, mas identificadas 19 presenças de 
variáveis (18\%). 0 total para os dois anos era de 198 possibilidades de acontecerem variáveis, com uma percepção de 30 acontecimentos, representando 15\% das possibilidades.

Em relação ao CMS, os números encontrados são significativamente maiores que dos outros conselhos. Em 2015, foram 324 possibilidades de encontrar as variáveis nas descrições das atas. Foram detectadas 141 ocorrências, ou 44\% de variáveis presentes nas reuniões do CMS. Para 2016, foram 288 possibilidades para a detecção das variáveis, sendo encontrados 136 acontecimentos. Embora o número de reuniões tenha sido menor que no ano anterior, proporcionalmente foi identificado um percentual maior de variáveis, correspondendo a $47 \%$ das possibilidades. No total dos dois anos, das 612 possibilidades de ocorrência das variáveis, foram identificadas 277 vezes, ou $45 \%$ do total.

A Tabela 5 apresenta a frequência relativa detalhada por variável analisada para cada um dos conselhos nos anos de 2015 e 2016 e no total do período.

Tabela 5 - Frequência relativa por variável analisada no CAE, CME e CMS (2015 e 2016)

\begin{tabular}{|c|c|c|c|c|c|c|c|c|c|}
\hline \multirow[b]{2}{*}{ Variáveis } & \multicolumn{3}{|c|}{ CAE } & \multicolumn{3}{|c|}{ CME } & \multicolumn{3}{|c|}{ CMS } \\
\hline & $\begin{array}{c}2015 \\
(n=13)\end{array}$ & $\begin{array}{l}2016 \\
(n=9)\end{array}$ & $\begin{array}{c}\text { Total } \\
(n=22)\end{array}$ & $\begin{array}{l}2015 \\
(n=5)\end{array}$ & $\begin{array}{l}2016 \\
(n=6)\end{array}$ & $\begin{array}{c}\text { Total } \\
(n=11)\end{array}$ & $\begin{array}{c}2015 \\
(n=18)\end{array}$ & $\begin{array}{c}2016 \\
(n=16)\end{array}$ & $\begin{array}{l}\text { Total } \\
(n=34)\end{array}$ \\
\hline $\mathrm{V} 1$ & - & - & - & - & - & - & $100 \%$ & $94 \%$ & $97 \%$ \\
\hline V2.1 & - & - & - & $80 \%$ & $83 \%$ & $82 \%$ & $100 \%$ & $100 \%$ & $100 \%$ \\
\hline V2.2 & - & - & - & - & $17 \%$ & $9 \%$ & $83 \%$ & $94 \%$ & $88 \%$ \\
\hline V2.3 & $23 \%$ & $22 \%$ & $23 \%$ & - & $33 \%$ & $18 \%$ & $61 \%$ & $69 \%$ & $59 \%$ \\
\hline V3.1 & $8 \%$ & $11 \%$ & $9 \%$ & $60 \%$ & $33 \%$ & $45 \%$ & $33 \%$ & $31 \%$ & $29 \%$ \\
\hline V3.2 & - & - & - & - & - & - & - & $6 \%$ & $3 \%$ \\
\hline V3.3 & $54 \%$ & $46 \%$ & $41 \%$ & - & $17 \%$ & $9 \%$ & $78 \%$ & $88 \%$ & $82 \%$ \\
\hline V3.4 & $8 \%$ & - & $4 \%$ & - & - & - & $33 \%$ & $44 \%$ & $38 \%$ \\
\hline V4.1 & $69 \%$ & $23 \%$ & $54 \%$ & - & - & - & $100 \%$ & $100 \%$ & $100 \%$ \\
\hline V4.2 & - & - & - & - & $17 \%$ & $9 \%$ & - & - & - \\
\hline V5 & $100 \%$ & $100 \%$ & $100 \%$ & $80 \%$ & $100 \%$ & $89 \%$ & $100 \%$ & $100 \%$ & $100 \%$ \\
\hline V6 & $23 \%$ & $23 \%$ & $27 \%$ & - & - & - & - & $19 \%$ & $9 \%$ \\
\hline V7.1 & - & - & - & - & - & - & $11 \%$ & $19 \%$ & $15 \%$ \\
\hline V7.2 & - & - & - & - & - & - & $11 \%$ & $13 \%$ & $12 \%$ \\
\hline V8.1 & - & - & - & - & $17 \%$ & $9 \%$ & $6 \%$ & $6 \%$ & $6 \%$ \\
\hline V8.2 & - & - & - & - & - & - & $22 \%$ & - & $12 \%$ \\
\hline V9.1 & $15 \%$ & - & $9 \%$ & - & - & - & $6 \%$ & - & $3 \%$ \\
\hline V9.2 & $31 \%$ & $56 \%$ & $41 \%$ & - & - & - & $39 \%$ & $69 \%$ & $53 \%$ \\
\hline
\end{tabular}

CAE = Conselho Municipal de Alimentação Escolar; CME = Conselho Municipal de Esportes; CMS = Conselho Municipal de Saúde; $V$ = variável; $n=$ número de reuniões. Fonte: Elaborada pelos autores.

O CMS foi o único dos conselhos que garantiu a participação de representantes do Estado, sociedade civil e mercado (V1). Nos demais, esteve ausente a participação, como membros do conselho, dos representantes do mercado.

Em relação ao registro de pronunciamento de conselheiros da área não governamental (V2.1), verificou-se a ocorrência na maioria das reuniões do CME do período (82\%) e na totalidade das reuniões do CMS (100\%). Não foi possível identificar o registro do pronunciamento dos conselheiros da área não governamental no CAE em razão da maneira adotada para o registro das atas. Da mesma forma, apenas no CME e no CMS foi viável identificar a participação de cidadão não conselheiro, sendo em $9 \%$ e $88 \%$ das reuniões, respectivamente. Quanto às deliberações voltadas às políticas públicas e/ou ações governamentais (V2.3), os três conselhos desempenharam essa atribuição: o CAE em 23\% das reuniões, o CME em 18\% e o CMS em 59\%, no total de 2015 e 2016.

Em relação à participação do conselho na consulta, no planejamento, na implementação e no controle das ações governamentais, bem como à fiscalização do uso de recursos públicos (V3.1), constatou-se que todos os conselhos apresentaram esse tipo de envolvimento: o CAE em 9\% das reuniões do período, o CME em 45\% e o CMS em 29\%. Já a variável de identificação de situação explícita de planejamento de ações governamentais e políticas públicas (V3.2) foi encontrada apenas no CMS em 2016 (3\% das reuniões do período), o que indica que os conselhos não têm participado constantemente 
do planejamento com o poder público. A prática do controle social por parte do conselho (V3.3) foi constatada em todos os conselhos, com destaque para o CMS (82\%) e CAE (41\%). No CME, verificou-se apenas uma ocorrência em 2016.

A representação de grupos vulneráveis (V.4.1) esteve assegurada apenas no CAE e no CMS, tendo sido identificada sua ocorrência em $54 \%$ e $100 \%$ das reuniões dos dois anos, respectivamente. Já a presença de representantes externos aos conselhos de grupos vulneráveis (V4.2) foi detectada apenas uma vez no CME, no ano de 2016.

Pelos pronunciamentos dos representantes, as atas registraram a presença dos conselheiros da sociedade civil (V5). Essa variável constou em 89\% das reuniões do CME e em 100\% das reuniões do CAE e do CMS.

No que se refere à participação dos conselheiros em capacitações técnicas e/ou políticas (V6), o CAE apresentou três registros de participações em capacitações em cada ano (27\% de todas as reuniões). Os conselheiros do CME não participaram nos anos pesquisados, enquanto os conselheiros do CMS participaram em 2016, em três situações (19\% das reuniões do ano). De acordo com os registros do CMS, foram os conselheiros locais e distritais que participaram de capacitações no período estudado.

Verificou-se ainda se as propostas de ações e de políticas públicas tiveram iniciativa dos próprios conselhos (V7.1) e, em caso afirmativo, se foram oriundas do segmento não governamental (V7.2). Apenas o CMS registrou a ocorrência dessas variáveis, em 15\% e 12\% das reuniões do período, respectivamente.

O relato de planejamento intersetorial (V8.1) não foi encontrado no CAE. Já no CME, houve o registro em uma única situação em 2016, e no CMS, uma em cada ano pesquisado. A variável V8.2, que trata da solução integrada de problemas, apareceu apenas no CMS, quatro vezes em 2015 (12\% do total de reuniões).

Sobre as presentes (V9.2) ou futuras (V9.1) descentralizações político-administrativas, o CME não deliberou nem tratou desses assuntos. O CAE e o CMS apresentaram a V9.1 em 9\% e 3\% das reuniões do período, e a V9.2 em $41 \%$ e $54 \%$ do total de reuniões, respectivamente.

De acordo com evidências obtidas na pesquisa, a participação direta do cidadão externo aos conselhos apresenta a mesma configuração para o CAE, o CME e o CMS, ou seja, é praticamente inexistente. Ressalva-se, no entanto, que o CMS relata constantemente que a participação popular vinha acontecendo nas reuniões ocorridas nas unidades de saúde e nos distritos sanitários, esferas não abrangidas por esta pesquisa.

Considerando que a governança pública tem um compromisso com o planejamento e os objetivos de longo prazo, constatou-se que essa perspectiva não esteve presente nas pautas das reuniões dos conselhos estudados. 0 período elencado para a pesquisa se refere aos dois últimos anos de gestão do poder executivo municipal, e esse pode ser um dos motivos pelo qual o planejamento não foi um tema frequente nas reuniões. Porém, tampouco pode ser descartada a hipótese de que a discussão e a deliberação do planejamento de ações governamentais e políticas públicas estejam ausentes dos conselhos gestores.

A descentralização político-administrativa (como convênios, acordos e parcerias de modo geral) e o deslocamento do poder estatal, visando ao equilíbrio de poder entre os atores, têm maiores possibilidades de se materializar em serviços públicos prestados com eficiência, eficácia, efetividade e equidade (Dias \& Cario, 2014). Essa interlocução multidimensional fica evidenciada no CMS, por apresentar em sua composição as três esferas de interesse envolvendo os serviços públicos. A descentralização político-administrativa ficou demonstrada no CAE e no CMS. Assim, a cooperação entre cidadãos, associações, empresas e demais segmentos da sociedade para com a gestão pública reforça o compartilhamento de responsabilidades entre as esferas de interesse.

Considerando-se que as variáveis investigadas foram encontradas em 18\% das 396 possibilidades do CAE, em 15\% das 198 possibilidades do CME e em 45\% das 612 possibilidades no CMS, conforme Tabela 4, isso equivale a dizer que a efetividade da participação cidadã aparece nessas mesmas 
proporções nos conselhos analisados. São porcentagens ainda muito baixas e que deixam a desejar no cumprimento do estabelecido nas legislações.

\section{Conclusão}

Por meio da revisão de literatura, foi definido um tipo ideal de governança pública, de acordo com o conceito da vertente democrática. Partindo do modelo de governança pública adotado, foi realizada a análise da prática dos conselhos sociais de Curitiba eleitos para o estudo (CAE, CME e CMS), comparando-os com as características ideais de governança e participação da sociedade civil nessa arena de interlocução entre governo e sociedade civil.

O diagnóstico da participação da sociedade civil nos conselhos estudados corrobora estudos anteriores, inferindo que tal participação está aquém do esperado. Entre os estudos estão: Fuks (2004), Santos et al. (2004), Martins et al. (2014), Diegues (2013), Dagnino \& Teixeira (2014), Avritzer \& Ramos (2016), Gohn (2016) e Pereira et al. (2016).

Considerando-se que, dos 21 conselhos sociais de Curitiba, apenas o CAE, o CME e o CMS apresentaram todas as fontes de coletas de dados estabelecidas pelo método de pesquisa, constatou-se que esses conselhos garantem, em suas legislações, a institucionalização da democracia participativa e do controle social. Esse enfoque pressupõe que as discussões e as tomadas de decisões podem acontecer tanto por meio de representantes quanto pela participação direta dos cidadãos.

As variáveis investigadas foram encontradas em poucas situações. Os percentuais muito baixos depõem contra a efetividade dos preceitos participativos estabelecidos nas legislações, inclusive na CRFB. Além disso, a participação ainda não corresponde ao tipo ideal defendido para a governança pública democrática.

Embora a sociedade civil esteja representada nos conselhos, a atuação dos conselheiros desse segmento ainda é limitada. Apesar da presença desses representantes na maioria das reuniões plenárias, poucas foram as ocasiões em que se manifestaram para fazer proposições e influenciar as decisões. Ressalva-se, porém, que o CMS é o conselho que apresentou maior maturidade de atuação, possivelmente por seus 27 anos de funcionamento. Em contraste, o CME foi o conselho que menos apresentou as características esperadas, talvez por causa do seu pouco tempo de existência.

Por fim, convém destacar que, de modo geral, a transparência das ações dos conselhos sociais também foi incipiente. Nem todos aderiram ao Portal dos Conselhos Municipais de Curitiba, ou disponibilizam informações, ou possuíam endereço eletrônico próprio.

Mesmo para aqueles cujas informações estavam disponíveis, a forma de redação das atas foi limitante para a avaliação da efetividade da participação cidadã. Isso porque o conselho pode apresentar, na prática, reuniões mais densas, com mais participação e deliberação, e essas situações podem não estar registradas nas atas. Esse possível cenário leva à necessidade de uma relativização dos achados empíricos deste estudo. 0 método possui limitações de captar a complexidade do objeto em análise. Porém, ele tem a vantagem de ser claro e objetivo, permitindo a replicabilidade do estudo.

Para suprir a limitação da pesquisa e buscar resultados mais completos, sugerem-se estudos utilizando entrevistas com os atores envolvidos e observação do funcionamento dos conselhos e atuação dos conselheiros. Este estudo não propõe esgotar a discussão nem apresentar conclusões definitivas sobre a democracia participativa nos conselhos gestores em prol da governança pública. Contudo, apresenta elementos que podem ampliar e subsidiar as reflexões relacionadas ao tema.

\section{Referências}

Alcântara, V., Pereira, J., \& Silva, É. (2015). Gestão Social e Governança Pública: aproximações e (de) limitações teórico-conceituais. Revista de Ciências da Administração, 1(3), 11-29. http://dx.doi.org/10.5007/2175-

8077.2015v17nespp11. 
Almeida, C., Cayres, D. C., \& Tatagiba, L. (2015). Balanço dos estudos sobre os conselhos de políticas públicas na última década. Lua Nova: Revista de Cultura e Política, (94), 255-294. http://dx.doi.org/10.1590/010264452015009400009.

Avritzer, L. (2008). Instituições participativas e desenho institucional: algumas considerações sobre a variação da participação no Brasil democrático. Opinião Pública, 14(1), 43-64. http://dx.doi.org/10.1590/S010462762008000100002.

Avritzer, L., \& Ramos, A. (2016). Democracia, escala y participación: reflexiones desde las instituciones participativas brasileñas. Revista Internacional de Sociologia, 74(3), e040.

http://dx.doi.org/10.3989/ris.2016.74.3.040.

Bercovici, G. (2008). O federalismo no Brasil e os limites da competência legislativa e administrativa: memórias da pesquisa. Revista Jurídica da Presidência, 10(90), 1-18. http://dx.doi.org/10.20499/2236-3645.RJP2008v10e90253.

Bevir, M. (2010). Democratic governance. New Jersey: Princeton University Press. http://dx.doi.org/10.1515/9781400836857.

Cepiku, D. (2008). Public Governance: research and operational implications from a literature review. In D. Cepiku, M. Meneguzzo, \& M. Senese (Eds.), Innovations in public management and governance in Italy (pp. 97-113). Roma: Aracne.

Cozzolino, L. F., \& Irving, M. A. (2016). Por uma concepção democrática de governança para a esfera pública. Revista de Políticas Públicas, 19(2), 497-508. http://dx.doi.org/10.18764/2178-2865.v19n2p497-508.

Curitiba. Prefeitura Municipal. (2011, 20 de dezembro). Lei orgânica municipal de Curitiba. Curitiba: Diário Oficial do Estado. Recuperado em 2 de março de 2019, de https://www.cmc.pr.gov.br/down/Lei_Organica.pdf

Curitiba. Conselhos Municipais de Curitiba. (2018). Recuperado em 2 de janeiro de 2018, de http://portaldosconselhos.curitiba.pr.gov.br/conselho-municipal-de-saude-social/

Dagnino, E., \& Teixeira, A. C. (2014). The participation of civil society in Lula's government. Journal of Politics in Latin America, 6(3), 39-66. http://dx.doi.org/10.1177/1866802X1400600303.

Dias, T., \& Cario, S. A. (2017). A gestão descentralizada adotada em Santa Catarina, o engajamento social e suas unidades regionais: de governo para governança no despontar do século 21. Revista Catarinense de Economia, 1(1), 183-210. Recuperado em 2 de março de 2019, de http://apec.pro.br/rce/index.php/rce/article/view/17

Dias, T., \& Cario, S. A. F. (2014). Sociedade, desenvolvimento e o papel estratégico do Estado: uma reflexão sobre o surgimento da governança pública. Ensaios FEE, 35(2), 337-362. Recuperado em 2 de março de 2019, de https://revistas.fee.tche.br/index.php/ensaios/article/view/2876

Diegues, G. C. (2013). O controle social e participação nas políticas públicas: o caso dos conselhos gestores municipais. Revista NAU Social, 4(6), 82-93. Recuperado em 2 de março de 2019, de https://portalseer.ufba.br/index.php/rs/article/view/31241/18609

Frey, K. (2004). Governança interativa: uma concepção para compreender a gestão pública participativa? Política e Sociedade, 3(5), 119-138. Recuperado em 2 de março de 2019, de https://periodicos.ufsc.br/index.php/politica/article/view/1982

Frey, K., \& Duarte, F. (2006). Auto-segregação e a gestão das cidades. Revista Ciências Sociais em Perspectiva, 5(9), 109-119. Recuperado em 2 de março de 2019, de http://erevista.unioeste.br/index.php/ccsaemperspectiva/article/view/1422/1154

Fuks, M. (2004). Democracia e participação no Conselho Municipal de Curitiba. In M. Fuks, R. M. Perissinotto, \& N. R. Souza (Eds.), Democracia e Participação: os Conselhos Gestores do Paraná. Curitiba: Editora UFPR.

Fuks, M., \& Casalecchi, G. A. (2018). Expandindo o conceito de competência política: conhecimento político e atitudes democráticas na América Latina. Revista de Sociologia e Politica, 26(68), 61-74.

http://dx.doi.org/10.1590/1678987318266802. 
Gohn, M. G. (2004). Conselhos municipais e a gestão urbana. In O. A. Santos, Jr., L. C. Q. Ribeiro, \& S. Azevedo (Eds.), Governança democrática e poder local: a experiência dos conselhos municipais no Brasil. Rio de Janeiro: Revan.

Gohn, M. G. (2011). Conselhos gestores e participação sociopolítica (4a ed.). São Paulo: Cortez.

Gohn, M. G. (2016). Gestão pública e os conselhos: revisitando a participação na esfera institucional. Revista de Estudos e Pesquisas sobre as Américas, 10(3), 1-15. Recuperado em 2 de março de 2019, de http://periodicos.unb.br/index.php/repam/article/view/14931

Gomes, E. G. (2015). Conselhos gestores de políticas públicas: aspectos teóricos sobre o potencial de controle social democrático e eficiente. Cadernos EBAPE.BR, 13(4), 894-909. http://dx.doi.org/10.1590/1679-395123196.

Instituto de Pesquisa Econômica Aplicada - IPEA. (2013). Conselhos nacionais: perfil e atuação dos conselheiros. Brasília: IPEA. Recuperado em 2 de março de 2019, de http://www.ipea.gov.br/participacao/images/pdfs/relatoriofinal_perfil_conselhosnacionais.pdf

Kleba, M. E., Comerlatto, D., \& Frozza, K. M. (2015). Instrumentos e mecanismos de gestão: contribuições ao processo decisório em conselhos de políticas públicas. Revista de Administração Pública, 49(4), 1059-1079. http://dx.doi.org/10.1590/0034-7612125666.

Lüchmann, L. H. H., Almeida, C., \& Gimenes, É. R. (2016). Gênero e representação política nos conselhos gestores no Brasil. Dados, 59(3), 789-822. http://dx.doi.org/10.1590/00115258201692.

Martins, M. F., Martins, S., Oliveira, A. R., \& Soares, J. B. (2014). Conselhos municipais de políticas públicas: uma análise exploratória. Revista do Serviço Público, 59(2), 151-185. http://dx.doi.org/10.21874/rsp.v59i2.144.

Matias-Pereira, J. (2010). Governança no setor público (1a ed.). São Paulo: Atlas.

Paula, A. P. (2005). Por uma nova gestão pública: limites e potencialidades da experiência contemporânea (1a ed.). Rio de Janeiro: Editora FGV.

Pereira, R. M., Roberto, R. F., Gava, R., \& Silva, E. A. (2016). Conselhos gestores de políticas públicas: relações entre estado e sociedade civil no contexto local. Revista de Gestão em Sistemas de Saúde, 5(1), 29-40.

http://dx.doi.org/10.5585/rgss.v5i1.196.

Rojas Buvinich, D. P. (2014). O mapeamento da institucionalização dos conselhos gestores de políticas públicas nos municípios brasileiros. Revista de Administração Pública, 48(1), 55-82. http://dx.doi.org/10.1590/S003476122014000100003.

Santos, O. A., Jr., Ribeiro, L. C., \& Azevedo, S. (2004). Democracia e gestão local: a experiência dos conselhos municipais no Brasil. In O. A. Santos, Jr., L. C. Q. Ribeiro, S. Azevedo (Eds.), Governança democrática e poder local: a experiência dos conselhos municipais no Brasil. Rio de Janeiro: Revan.

\section{Editor: Rodrigo Firmino}

Recebido: Mar. 02, 2019

Aprovado: Nov. 17, 2019 